Revista de Filología Románica

ISSN: 0212-999X

http://dx.doi.org/10.5209/RFRM.63511

\title{
O barranquenho: urgência de uma política linguística? ${ }^{1}$
}

\author{
Victor Manuel Diogo Correia²
}

Recibido: 26 de marzo de 2018 / Aceptado: 3 de septiembre de 2018

Resumo. No século XXI, o barranquenho enfrenta a ameaça da globalização e consequente processo de nivelamento com o português. A reflexão sobre a realidade do barranquenho constitui-se como um factor decisivo na definição de rumos de política linguística para esta variedade de contacto. No entanto, qualquer política deve envolver a comunidade de falantes, o que implica a verificação in situ da existência de uma consciência linguística e as suas tendências. Entre os tópicos que foram objecto de inquérito na comunidade, incluem-se questões de adscrição, vitalidade, projecção no exterior, consciência da variação no próprio barranquenho e motivação para a protecção e desenvolvimento da língua.

Palavras-Chave: Barranquenho; contacto de línguas; atitudes linguísticas.

\section{[en] Barranquenho: urgency of a linguistic policy?}

\begin{abstract}
In the 21st century, Barranquenho faces the threat of globalization and consequent leveling with Portuguese. The reflection on the reality of Barranquenho is a decisive factor in the definition of directions of linguistic policy for this contact variety. However, any policy should involve the community of speakers, which implies in situ verification of the existence of a linguistic awareness and its trends. Topics covered in the community include questions of ascription, vitality, projection abroad, awareness of the variation in Barranquenho itself and motivation for the protection and development of this language.
\end{abstract}

Key words: Barranquenho, language contact, linguistic attitudes.

Sumário. 0. Introdução. 1. Metodologia. 2. Apresentação de dados linguísticos. 2.1. Identidade linguística. 2.1.1. Questões de glotonímia. 2.1.2. Adscrição linguística do barranquenho. 2.2. Uso do barranquenho. 2.2.1. Em relação com o passado. 2.2.2. Em projecção futura. 2.3. Importância dos direitos estatuários. 2.3.1. Contraste com uma situação linguística (externa). 2.3.2. Contraste com uma situação cultural (interna). 2.4. Valorização nas modalidades oral e escrita. 2.4.1. Vontade de mostrar como é o barranquenho. 2.4.2. Utilidade da produção escrita. 3. Análise conclusiva dos resultados. 4. Referências bibliográficas.

Cómo citar: Diogo Correia, V.M. (2019).O barranquenho: urgência de uma política linguística?, en Revista de Filología Románica 36, 169-178.

\footnotetext{
1 Texto lido a 04.04.2017 nas VI Jornadas Internacionales de Lingüistica Hispánica. Variación e Identidad. Faculdade de Letras da Universidade de Lisboa 3, 4 e 5 de abril de 2017.

2 Universidade de Évora. CIDEHUS-UE/FCT- UID/HIS/00057/2013 (POCI-01-0145-FEDER-007702) vdiogoc@hotmail.com
} 


\section{Introdução}

Tratando-se de uma variedade minoritária, facilmente se adivinha a resposta afirmativa à questão introduzida no título do presente texto, "O barranquenho: urgência de uma política linguística?". O barranquenho é uma variedade falada na comunidade raiana de Barrancos (distrito de Beja, Portugal)- ou fora dela entre conterrâneos numa ambiência marcada pelo hibridismo cultural. A língua é falada em regime de bilinguismo diglóssico, com o português e o espanhol nas suas variedades meridionais. Os falantes mudam de código linguístico de acordo com a origem do interlocutor (Vasconcelos 1955: 30), sendo que esta situação é mencionada orgulhosamente pelos barranquenhos quando são questionados sobre os usos linguísticos na comunidade. Língua de contacto com características peculiares dentro da sua tipologia, segundo V. Navas (2015: 84) constitui um caso único na Península Ibérica. Formou-se a partir de variedades meridionais ibéricas: alentejano, estremenho e andaluz e terá surgido de uma situação de bilinguismo desigual por volta do séc. XV/XVI.

No referente ao consonantismo, os traços fonético-fonológicos mais emblemáticos são a realização da sibilante em coda como aspirada ou a sua elisão, o betacismo e a apócope de $<\mathrm{l}>$ e $<\mathrm{r}>$, tendencialmente em fronteira de palavra (Navas 2011: 55-57). No âmbito do vocalismo, destaca-se a tendência para o não levantamento da vogal $<$ e, a, o $>$ em posição átona e a redução dos ditongos $<$ ei $>$ e $<$ ou $>$ em sílaba tónica (Navas 2011: 196). Destacam-se, como traços peculiares no âmbito da morfossintaxe, a estrutura híbrida dos clíticos antes de forma verbal, v.g. (...) também sas levou a minha filha (Navas 2011: 65); e o uso do pretérito perfeito composto com o marcador temporal hoje, como em espanhol, embora com o auxiliar ter como em português, v.g. Não, tenho visto há mais dias, sim (Navas 2011: 66; Amaral 2016). Quanto ao léxico e fraseologia, embora maioritariamente de base portuguesa, verificam-se alguns calcos do espanhol de partículas gramaticais, v.g. pero (Navas 1997: 263) e de palavras de uso comum, v.g. perrunilhas (Navas 2000: 385). Para ilustrar a riqueza da fraseologia, veja-se o provérbio, v.g. Quien fue a Sevilla, perdió su silla (Franco 2005: 88), embora também se possam apresentar calcos de outras estruturas próprias do espanhol meridional, tal como escutámos na comunidade, v.g. barrq. estar de paporrita ("estar a dormir de barriga para cima") / esp. estar a la paporrita (Garrido 2017: 38). Em suma, o isolamento secular e o contacto privilegiado entre as variedades meridionais castelhano-leonesas e portuguesas constituíram as condições ideais para a formação do barranquenho.

\section{Metodologia}

Servem-nos como base de trabalho, os resultados de um inquérito linguístico aplicado em Barrancos, nos dias 29, 30 e 31 de Maio de 2014, a 52 informantes. As variáveis extralinguísticas presentes nesse inquérito são o género e a faixa etária. Trata-se, pois, de 21 indivíduos do sexo masculino e 31 do sexo feminino, repartidos por três grupos etários: o grupo I (entre 14-16 anos); o grupo II (entre 20-38 anos) e o grupo III, com uma faixa etária compreendida entre 41 e 56 anos. Em termos absolutos o individuo mais novo tinha 14 anos e o mais velho 56 anos. Os limites impostos para este texto condicionaram a escolha de alguns tópicos de análise. Neste caso, faremos 
uso de 7 questões que, do universo total de 26, nos parecem bastante ilustrativas do referido inquérito. Os resultados percentuais encontram-se apresentados em termos absolutos, i.e., não procederemos a leituras parciais em termos das variáveis faixa etária ou género.

\section{Apresentação de dados linguísticos}

Os dados linguísticos que passamos a analisar incidem nos temas da identidade linguística, uso da língua, importância dos direitos estatuários e valorização no âmbito das modalidades oral e escrita.

\subsection{Identidade linguística}

A identidade linguística de uma comunidade pode ser abordada sob várias perspectivas de análise. Pela especificidade que apresentam no caso barranquenho, pareceram-nos pertinentes as questões da glotonímia e da adscrição linguística.

\subsubsection{Questões de glotonímia}

Contrariamente ao que se passa em muitas outras comunidades linguísticas, em Barrancos o glotónimo utilizado pelos falantes e pelos académicos é o mesmo: $b a$ rranquenho. Também surge designado noutras línguas como barranqueño (espanhol) e barranquian (inglês). A título de curiosidade, com o termo barranquenhada (Vasconcelos 1955: 10) reportam-se os falantes a uma palavra ou expressão muito própria desta língua. Cumpre ainda dizer que na publicação Ethnologue o barranquenho também aparece com os nomes alternativos de cahtúo, cahtúö, extremaduran, ehtremeñu e extremeño integrado no código ISO 639-3: ext para o extremenho. ${ }^{3}$

\subsubsection{Adscrição linguística do barranquenho}

A adscrição do barranquenho e a sua consideração, ou não, como língua foi testada através da introdução de três opções de resposta que permitem ao informante colocar-se numa posição que vai do maior afastamento - em termos dialectométricos até à valorização mais negativa e próxima ao português.

Questão 1: O barranquenho é

Opções de resposta

a) Português com algumas incorrecções

b) Português com características antigas
Resultados (\%)
13.5

51.9

\footnotetext{
Em http://www.ethnologue.com/show_language.asp?code=ext [Consultado em 13.01.2013].
} 
c) Uma língua diferente do português

32.7

Votos nulos

Total

100

Quadro 1

A opção mais votada foi a b) com 51,9\%, seguida da alínea c) com 32,7\% e da a) com $13,5 \%$. O único voto nulo representa $1,9 \%$ do total das votações. Vale dizer que 5 em cada 10 pessoas entendem que o barranquenho é português com características antigas; o barranquenho é considerado uma língua diferente do português numa razão de 3 por cada 10 pessoas e, verdadeiramente, só uma em cada 10 pessoas considera que o barranquenho é português com incorrecções. Perante os dados apresentados, pode-se constatar que os informantes não têm dúvidas em distinguir o barranquenho como uma realidade linguística diferente, e bem distanciada, do português falado actualmente.

\subsection{Uso do barranquenho}

No que respeita à consciência linguística sobre o uso/vitalidade do barranquenho, pareceu-nos interessante - de resto, a exemplo de outros inquéritos linguísticos estabelecer a análise numa perspectiva diacrónica, i.e., o informante manifesta-se, não só em relação ao passado, mas também em projecção futura. Com a introdução da componente diacrónica pretendemos verificar até que ponto os informantes têm consciência da situação de risco que poderá enfrentar o barranquenho num futuro próximo como variedade minoritária sem políticas de normalização.

\subsubsection{Em relação com o passado}

\section{Questão 2: O barranquenho}

\section{Opções de resposta}

Resultados (\%)

a) Já se fala menos agora do que há uns anos

65.4

b) Fala-se mais agora do que antes

3.8

c) É tão falado agora como era antes

30.8

\section{Votos nulos}

0

\section{Total}

100 
A opção a) soma $65,4 \%$ das preferências de resposta, seguida de c) com $30,8 \%$ e de b) com apenas 3,8\% dos votos. Os dados permitem-nos estabelecer uma relação de proporcionalidade, na qual 7 em cada 10 pessoas consideram que o barranquenho é actualmente falado por menos pessoas do que há uns anos, sendo que $3 \mathrm{em} 10$ opinam que a língua é tão falada quanto o era antes. Apenas 2 informantes escolhem a opção b), pelo que praticamente não tem expressão a ideia de que a língua é mais falada na actualidade.

\subsubsection{Em projecção futura}

Questão 3: Como será daqui a 20 anos?

Opções de resposta

a) O barranquenho será cada vez menos falado

b) O barranquenho será cada vez mais falado

c) A situação será igual à dos dias de hoje

Votos nulos
Resultados (\%)

38.5

\section{Quadro 3}

Em projecção futura, a opção c) recolhe a maioria das escolhas dos informantes com 55,8\% dos votos; a opção a) soma 38,5\% e, por último, a alínea b), com apenas $5,8 \%$ das preferências. Dito de outro modo, 6 em 10 pessoas crêem que, dentro de 20 anos, o barranquenho será tão falado como é agora, mas cerca de 4 em 10 pessoas opinam que a língua será cada vez menos falada. Face a estes dados, julgamos poder detectar algum optimismo em relação ao futuro, embora muito relativizado, pois a alínea a) congrega um número bastante considerável de votantes.

\subsection{Importância dos direitos estatuários}

Para detectar a importância atribuída pelos falantes à conquista de direitos estatuários para o barranquenho, usámos duas situações distintas como termo de comparação: uma apresenta um contraste com uma situação linguística externa - a oficialização do mirandês; a outra é uma comparação com uma situação interna, própria de Barrancos, que constituiu um debate bastante polémico em Portugal: trata-se da legalização dos touros de morte (Franco 2005: 201 e ss.). 


\subsubsection{Contraste com uma situação linguística (externa)}

Questão 4: Acha que o barranquenho deve ser protegido oficialmente, a nível nacional, tal como é o mirandês?

Opções de resposta

a) Concordo plenamente

b) Não me parece bem

c) É indiferente
Resultados (\%)

\section{Votos nulos}

Total
86.5

0

\section{5}

0

100

\section{Quadro 4}

No que respeita à conquista de direitos estatuários linguísticos, verifica-se que em termos percentuais, a opção a) é a mais pontuada com 86,5\% do total de votações, à qual se segue a opção c) com $13,5 \%$ das escolhas. A opção b) não recebe nenhum voto. Equivale a dizer que 9 em cada 10 pessoas concordam plenamente com a protecção oficial ao barranquenho, tal como sucedeu com o mirandês. Só 1 informante em 10 se considera indiferente perante a questão. Não se verifica oposição por parte dos inquiridos relativamente a esta possível oficialização do barranquenho.

\subsubsection{Contraste com uma situação cultural (interna)}

Questão 5: Proteger oficialmente o barranquenho a nível nacional é culturalmente

Opções de resposta

Resultados (\%)

a) Mais importante do que foi a legalização dos touros de Barrancos

21.2

b) Menos importante do que foi a legalização dos touros de Barran$\cos$

9.6

c) Tão importante como foi a legalização dos touros de Barrancos

65.4

\section{Votos nulos}

3.8

Total

100 
Comparativamente à importância dada à morte dos touros e sua legalização, os falantes manifestam-se do seguinte modo relativamente à língua: a opção c) soma a maioria das escolhas dos informantes com $65,4 \%$ dos votos seguida de a) com $21,2 \%$ e da opção b) com 9,6\%. Os votos nulos perfazem 3,8\% do total. Proporcionalmente, 7 em cada 10 pessoas consideram que proteger legalmente o barranquenho é tão importante como foi a protecção dada à lide dos touros, tradição tão cara à comunidade. Para 2 em cada 10 pessoas a protecção ao barranquenho é mais importante que a protecção dada aos touros e só 1 em cada 10 pessoas considera que a protecção aos touros é mais importante.

\subsection{Valorização nas modalidades oral e escrita}

A valoração atribuída pelos informantes ao barranquenho nas modalidades oral e escrita encontra-se avaliada por meio de duas questões: a primeira diz respeito à vontade que os falantes têm em mostrar como é o barranquenho e a segunda reporta-se à utilidade da produção escrita nesta língua.

\subsubsection{Vontade de mostrar como é o barranquenho}

Questão 6: Quando outros portugueses vêm a Barrancos, caso lhe peçam para falar o barranquenho

\begin{tabular}{lc}
\hline Opções de resposta & Resultados (\%) \\
\hline a) Gosto de mostrar como é o barranquenho & 80.8 \\
\hline b) Tenho alguma vergonha em falar barranquenho com estranhos & 17.3 \\
\hline c) Não falo barranquenho porque é uma língua só da comunidade & 0 \\
\hline Votos nulos & 1.9 \\
\hline Total & 100 \\
\hline
\end{tabular}

\section{Quadro 6}

De acordo com a expressão do desejo de falar o barranquenho perante estranhos, a alínea a) recolhe a grande maioria das escolhas dos inquiridos com $80,8 \%$, seguida de b) com apenas $17,3 \%$. Não existem votantes na alínea c) e os votos nulos correspondem a $1,9 \%$ do total. Pode concluir-se que em cada 10 informantes cerca de 8 gostam de mostrar como é o barranquenho a pessoas estranhas à comunidade, sendo que apenas um informante (em cada 10) revela ter vergonha de falar o barranquenho na situação anteriormente referida. 


\subsubsection{Utilidade da produção escrita}

Questão 7: Escrever em barranquenho será mais útil para

\section{Opções de resposta}

a) Textos de revistas, de jornais e de outras publicações

b) Registo das lendas, contos, poesia popular

c) Informações de rua, folhetos turísticos, ementas, rótulos de embalagem de produtos típicos

d) Traduzir obras de escritores famosos como Eça de Queiroz ou J. Saramago

Votos nulos

Total
Resultados (\%)

7.7

65.4

\section{3}

\section{8}

100

\section{Quadro 7}

No que respeita à produção escrita, a opção mais votada é a b) com $65,4 \%$ das escolhas. A grande distância, em termos percentuais, posicionam-se a opção c), com $17,3 \%$, e a opção a), com 7,7\% das preferências. A opção d) apenas pontua com $3,8 \%$ do total geral. Regista-se um total de 5,8\% de votos nulos nesta questão. Em termos de proporção, em cada 10 informantes 7 consideram que a utilidade da escrita em barranquenho serve para registo das lendas, contos, poesia popular; apenas 2 pessoas em cada 10 vislumbram o uso escrito do barranquenho em informações de rua, folhetos turísticos, ementas, rótulos de embalagem de produtos típicos e as demais opções praticamente não têm expressão em termos de escolha pelos informantes.

\section{Análise conclusiva dos resultados}

Com base nos dados numéricos resultantes do inquérito atrás exposto, podemos concluir que o barranquenho enfrenta um paradoxo relativamente aos índices de vitalidade, o que se torna preocupante devido ao quase desconhecimento, por parte dos informantes, do perigo real a que a sua língua está sujeita. Se existe, por um lado, transmissão geracional, pois as crianças falam barranquenho e a língua é usada por quase todos na comunidade, por outro, o número de falantes na vila já não chega aos 1800 indivíduos. Acresce o facto de que entre 2011 e 2014 (segundo estimativas anuais da Câmara Municipal de Barrancos) o número de residentes diminuiu em 80 indivíduos. Em 2001, eram 1924 habitantes; em 2011, passaram a 1834 e, em 2014, foram estimados em 1754 (Câmara Municipal de Barrancos 2016: 7). A elevada taxa de desemprego e a consequente emigração têm contribuído para estes números pouco animadores. 
Quando tomamos as impressões dos falantes numa projecção em termos diacrónicos sobre a vitalidade da língua, verifica-se que estes reconhecem a diminuição do seu uso em relação ao passado, mas a maioria não prevê a continuidade dessa tendência decrescente no futuro. Outro dado importante sobre a vitalidade - embora se encontre fora do rol dos dados apresentados nestas páginas - é o facto de os falantes se aperceberem indirectamente do crescente nivelamento do barranquenho com o português, conforme se deduz da valorização atribuída à língua falada pelos mais velhos: mais bonita e de melhor qualidade. Os mais jovens são os que consideram o barranquenho como "português mal falado" e sentem mais vergonha em falar a língua perante pessoas externas à comunidade.

Relativamente à possibilidade de desenvolvimento da língua no que respeita ao âmbito do aumento do corpus, i.e., à evolução da produção de textos escritos de várias tipologias em barranquenho, nota-se que os informantes apresentam dificuldade no reconhecimento da importância da textualização e da codificação para o já mencionado processo de normalização.

No que concerne ao desenvolvimento da textualização em barranquenho, verifica-se a preferência por um registo informal, semelhante ao que existe na oralidade, i.e., segundo os informantes, a possível produção escrita nesta língua deverá centrar-se em tipologias menos formais, de teor mais prático e num contexto cultural inerente à vivência no seio da comunidade.

Talvez possamos detectar nestes resultados alguma valorização negativa relativamente ao barranquenho, visto que esta língua parece não ser propícia para a tradução de obras canónicas da literatura portuguesa, vocacionadas essencialmente para fruição. O desenvolvimento do status aparece ensombrado - como em muitas outras comunidades de línguas minoritárias - por falsas crenças de natureza vária. Podemos apontar como exemplo o facto de o reconhecimento do barranquenho como Património Cultural Imaterial de Interesse Municipal em 2008 (Navas 2015: 19) ser encarado por muitos falantes como medida suficiente para proteger a língua; ou, ainda, a ideia de que o ensino do barranquenho é prejudicial para a aprendizagem do português. Por último, surge também algumas vezes a suspeita de que a normalização do barranquenho contribui para acelerar o seu desaparecimento.

Para finalizar, e, dando resposta à questão inicial, consideramos serem urgentes a consciencialização/mobilização na comunidade a favor da protecção do barranquenho. O desenvolvimento do processo de codificação é uma medida fundamental para potenciar a visibilidade da língua, bem como a criação de oportunidades e alargamento de contextos de uso do barranquenho, seja individualmente e/ou em grupo, seja na comunidade e /ou para o exterior. Vêm a este propósito as palavras de V. Navas (2000: 387) que ilustram cabalmente o que acabamos de referir:

[...] tal vez sea en la enseñanza obligatoria donde se deban dar los pasos necesarios de manera a llevar a cabo una política adecuada, para evitar quizá una actitud represiva por parte del profesorado que pueda conducir a la desaparición del dialecto

Assim, e para concluir, a escola deve ser vista como parte essencial do processo de desenvolvimento do barranquenho, e não como elemento opositor. A defesa deverá ser levada a cabo no sentido de "dentro para fora", pois é na atitude positiva das crianças que se poderá encontrar alguma garantia de futuro para a língua barranquenha. 


\section{Referências bibliográficas}

Amaral, Patrícia (2016): “The Present Perfec borders. A study in language contact”. Journal of Pidgin and Creole Languages 31, 1: 16-41.

Câmara Municipal de Barrancos (2016): Programa Estratégico de Reabilitação Urbana. [PERU_BARRANCOS\%20_FINAL_maio_16.pdf] [Consultado em 11.03.2017].

Franco, Norberto (2005): O Porquê de Barrancos. Barrancos: Município de Barrancos.

Garrido Palacios, Manuel (2017): Diccionario de palabras de andar por casa (Huelva y provincia). Huelva: Servicio de Publicaciones de la Universidad de Huelva.

Lewis, M. Paul (ed.) (2009): Ethnologue: Languages of the World. 16 ${ }^{\mathrm{a}}$ ed. Dallas: Sil International. (http://www.ethnologue.com/show_language.asp?code=ext) [Consultado em 13.01.2013].

Navas Sánchez-Élez, M. a Victoria (1996): “Transferencias morfológicas del castellano a un dialecto de base portuguesa, el barranqueño", Revista de Filología Románica, 13, pp. 253-266. Madrid: Universidad Complutense.

Navas Sánchez-Élez, Ma Victoria (2000): "Procesos de creación de las lenguas fronterizas", Revista de Filología Románica, 17, pp. 367-391. Madrid: Universidad Complutense.

Navas Sánchez-Élez, Ma Victoria (2011): El barranqueño: un modelo de lenguas en contacto. Madrid/Lisboa: UCM/CLUL.

Navas Sánchez-Élez, Ma Victoria (2015a): “El barranqueño, lengua oral versus lengua estándar: estado de la cuestión", Luenga \& fablas 19, pp. 83-89.

Navas Sánchez-Élez, Ma Victoria (2015b): “Actitudes lingüísticas en una situación de contacto de lenguas", Revista de Filología Románica 32, 1, pp. 11-20. Madrid: Universidad Complutense.

Vasconcelos, José Leite De (1955): Filologia barranquenha. Apontamentos para o seu estudo. Lisboa: Imprensa Nacional; reed. facs. 1981. 